\title{
Evaluation of Asbestos Exposure Associated with Research Laboratories
}

\author{
Ediberto Garcia, Daniel Newfang, Jayme Coyle, Giffe T. Johnson, Raymond D. Harbison \\ Center for Environmental and Occupational Risk Analysis and Management, College of Public Health, University of South \\ Florida, Tampa, FL, USA \\ Email:rharbiso@health.usf.edu
}

How to cite this paper: Garcia, E., Newfang, D., Coyle, J., Johnson, G.T. and Harbison, R.D. (2019) Evaluation of Asbestos Exposure Associated with Research Laboratories. Occupational Diseases and Environmental Medicine, 7, 13-20.

https://doi.org/10.4236/odem.2019.71002

Received: January 24, 2019

Accepted: February 18, 2019

Published: February 21, 2019

Copyright (c) 2019 by author(s) and Scientific Research Publishing Inc. This work is licensed under the Creative Commons Attribution International License (CC BY 4.0).

http://creativecommons.org/licenses/by/4.0/

\begin{abstract}
Asbestos containing materials (ACM) have been used for decades in research laboratory products including gloves, tong sleeves, Transite board, and other materials. These materials typically contain chrysotile asbestos with concentrations ranging up to $80 \%$. The objective of this research was to evaluate asbestos exposure from gloves, tong sleeves, and Transite board with simulated laboratory use. An environmental chamber was used to simulate laboratory application of the products. Bulk samples of various products were tested before and after use. Personal breathing zone air samples as well as one cumulative air sample were collected during testing and followed the National Institute for Occupational Safety and Health (NIOSH) 7400/7402 methodologies. Phase contrast microscopy (PCM) and transmission electron microscopy (TEM) were used for sample analyses. Analysis of air samples using PCM, showed airborne fiber concentrations as high as $0.058 \mathrm{f} / \mathrm{cc}$ during use of tongs fitted with asbestos sleeves. Further analysis using TEM showed that the highest airborne fiber concentration was $0.0036 \mathrm{f} / \mathrm{cc}$. Manipulation of Transite board resulted in 8-hour time-weighted-average (TWA) asbestos levels as high as $0.02 \mathrm{f} / \mathrm{cc}$. Testing of various asbestos containing materials used in research laboratories indicate low potential for asbestos fiber exposures.
\end{abstract}

\section{Keywords}

Asbestos, Exposure, Research Laboratories, Transite Board, Tong Sleeves, Gloves, Chrysotile Asbestos, Laboratory Products, Asbestos-Related Disease, Asbestos-Containing Material

\section{Introduction}

Asbestos is a generic term given to the fibrous variety of six naturally occurring minerals that have been used in a variety of commercial products. Its importance 
in products derives from its strength, heat resistance, flexibility, weavability, its ability to resist chemical and thermal degradation, and high electrical resistance. This fibrous material has been used as a component in thousands of construction, industrial, and household products including roofing and siding shingles, friction products in automobile parts, thermal systems insulation and electrical wiring, personal protective gear, and in certain laboratory equipment components [1]. Peak demand for asbestos was achieved around 1977, when about 25 countries were producing a total of almost $4.8 \mathrm{Mt}$ annually, with about 85 countries manufacturing these products. In the United States, and to a lesser extent, in many European countries, due to public opposition, the use of ACM waned in the early to late 1970s due to the growing research linking this wonder material to serious health effects [2]. By the mid-1970s, as mentioned above, due to health concerns and increasing regulatory requirements, the asbestos contents in ACM, including insulation products, decreased significantly due to its being substituted by other insulation materials such as fiberglass [3]. However, there have been concerns that exposure to asbestos outside the high exposure, insulation environment may have been elevated enough to lead to asbestos-related disease, specifically lung cancer, asbestosis, and mesothelioma. Among these low-exposure occupations are laboratory workers.

Health concerns were associated with asbestos being classified as a known human carcinogen. In addition, during residency in the lungs, a significant immunological response occurs that facilitates clearance [4] [5] that may also cause lung injury. Several occupations with known heavy asbestos exposure have been associated with asbestos-related disease which includes insulators, shipyard workers, and textile workers. However, other occupations where workers were routinely exposed to ACM products such as heavy construction equipment, automobile brakes, and plane parts have not shown airborne asbestos concentrations above the regulatory Occupational Safety and Health Administration (OSHA) Permissible Exposure Level (PEL) of $0.1 \mathrm{f} / \mathrm{cc}$, which is a level that is not expected to result in adverse health effects including asbestos-related disease [6] [7] [8] [9] [10]. This supposition is consistent with the lack of epidemiological evidence for enhanced asbestos-related disease among multiple occupational cohorts [9] [11] [12].

To date, few studies have documented exposure assessments involving ACM in the research laboratory environment. As well, the few published articles that do exist have primarily focused on gloves and mitts. Laboratories have used and continue to use a variety of ACM, primarily in applications where thermal insulation is required. In order to assess potential exposure risk while using ACM in a laboratory setting, a series of experiments were conducted in a contained environmental chamber to simulate high exposure "worst-case scenarios" that a laboratory technician might encounter while using an asbestos-containing product. This study reports the exposures measured from the use of asbestos containing gloves, tong sleeves, and Transite board. 


\section{Methods}

The experiments were conducted in an enclosed chamber (dimensions $=3 \mathrm{ft} \times 7$ $\mathrm{ft}$ ). Each item was individually tested with cleaning of the chamber between tests. The sampling filters were placed 18 inches above the worktable as well as the test material to represent the breathing zone of a laboratory technician. Each sample was collected for 30-minutes. There was one cumulative sample that was run in parallel to all of the individual 30 -minute tests (4.5 hour total cumulative exposure). Three used gloves, three used tongs (with asbestos-containing sleeves), and three Transite boards were manipulated and tested. During each test, participants manipulated the item for the entire 30 minutes and $>50 \%$ of the time more "aggressive" handling was applied. In all testing runs, there were visible fibers on the table that broke off from the test item. The Transite board manipulation included drilling between 12 to 18 holes, cutting it with a saw, chiseling it, and smashing it with a hammer. At the end of the Transite board test, there was dust spread over both horizontal and vertical surfaces (sheeting) in the chamber. The manipulations of the ACM during sample collection were severe to provide the greatest opportunity for fiber release. As well, these air samples were collected in an isolated exposure chamber prohibiting the escape of fibers producing a worst-case exposure scenario.

Air sampling was performed in accordance with NIOSH methods 7400/7402 recommendations: mixed cellulose ester membrane filters with $0.8 \mu \mathrm{m}$ pores inside $25 \mu \mathrm{m}$ diameter electrically conductive, extended cowl cassettes. Personal breathing zone sample flow rates were in the $15 \mathrm{~L} / \mathrm{min}$ range for gloves, tong sleeves, and Transite board. All PCM-intended sampling had a corresponding TEM sample obtained. All tested materials had pre-test bulk sampling performed. Laboratory personnel conducting the experiments were trained to handle ACM and used appropriate personal protective equipment during testing.

\section{Results}

Asbestos-containing products including gloves, tong sleeves, and Transite board were evaluated during the study. The nine collected bulk samples tested were found to have a variable amount of asbestos (Table 1). All items tested had between $30 \%$ to $45 \%$ chrysotile asbestos, except for the Transite board, which had only $10 \%$ chrysotile (in addition to $5 \%$ amosite). Cellulose was the most abundant non-asbestos material for all samples except from the Transite board (which also contained cement). From one large Transite board, three smaller size boards were sectioned and were individually tested for sample runs seven through nine.

All sample exposure measurements obtained were intended to represent personal breathing zone samples (also reported as the regulatory adjusted 8-hour TWA; Table 2). Out of three gloves, three tong sleeves, and three Transite board samples, two of the samples had identifiable fibers under PCM. Samples four through seven (the tongs) had exposure concentrations by PCM of 0.056 to 
Table 1. Bulk sample results.

\begin{tabular}{ccccc}
\hline $\begin{array}{c}\text { Bulk Sample } \\
\text { Designation }\end{array}$ & $\begin{array}{c}\text { Sample Run } \\
\text { Order }\end{array}$ & Item Type & $\begin{array}{c}\text { Chrysotile Asbestos } \\
\text { (unless otherwise noted) }\end{array}$ & Cellulose \\
\hline 3 & 1 & Glove & $40 \%$ & $50 \%$ \\
9 & 2 & Glove & $35 \%$ & $55 \%$ \\
5 & 3 & Glove & $30 \%$ & $65 \%$ \\
6 & 4 & Tong & $45 \%$ & $50 \%$ \\
$7 \mathrm{~A}$ & 5 & Tong & $40 \%$ & $55 \%$ \\
$12 \mathrm{~A}$ & 6 & Tong & $35 \%$ & $55 \%$ \\
$11^{*}$ & 7 & Transite & $10 \%(5 \%$ Amosite) & Cement \\
$11^{*}$ & 8 & Transite & $10 \%$ (5\% Amosite) & Cement \\
$11^{*}$ & 9 & Transite & $10 \%$ (5\% Amosite) & Cement \\
\hline
\end{tabular}

${ }^{*} 11$, These represent the same bulk sample from which the tested boards for runs $8-10$ were obtained.

Table 2. Personal breathing zone samples.

\begin{tabular}{ccccc}
\hline Sample \# & Sample Type & PCM (f/cc) & TEM (f/cc) & $\begin{array}{c}\text { 8-hour TWA } \\
\text { (PCM/TEM) }\end{array}$ \\
\hline 1 & Glove & -- & -- & -- \\
2 & Glove & -- & -- & -- \\
3 & Glove & -- & -- & - - \\
4 & Beaker tong sleeve & 0.056 & $<0.006$ & $--/$ BDL \\
5 & Beaker tong sleeve & -- & $<0.006$ & $0.0036 / 0.01$ \\
6 & Beaker tong sleeve & 0.058 & 0.160 & $--/ 0.013$ \\
7 & Transite & -- & 0.210 & -- \\
8 & Transite & -- & -- & $--/ 0.02$ \\
9 & Transite & -- & 0.320 & -- \\
\hline
\end{tabular}

“-”, Samples were not analyzed due to dust overload. BDL, Below the detection limit.

$0.058 \mathrm{f} / \mathrm{cc}$. Tong sleeve sample six, however, was overloaded with dust and could not be analyzed. The TEM results for the tongs identified that two out of three samples had an undetectable fiber load $(<0.006 \mathrm{f} / \mathrm{cc})$ while one sample had a fiber count of $0.160 \mathrm{f} / \mathrm{cc}$. These results further demonstrate the value of confirming PCM fiber counts with TEM as PCM may grossly overestimate asbestos exposure. The benefit of TEM analysis is that it measures only asbestos fibers, while PCM reports both asbestos and non-asbestos fibers, which is the reason for the potential overestimation of asbestos fibers. For the Transite board samples, all the PCM samples were unable to be analyzed due to being overloaded with dust. Two of the Transite board TEM samples had asbestos concentrations of 0.210 and $0.320 \mathrm{f} / \mathrm{cc}$, respectively. The third Transite board TEM sample was unable to be analyzed due to being overloaded with dust. Extrapolating the 8-hour TWA, assuming the exposures occurred once in an 8-hour work period, 
are also reported. To obtain the 8-hour TWA concentration, the values from the PCM and TEM columns were divided by 480 (minutes) and then multiplied by 30 (minutes). The glove samples and the cumulative sample were unable to be analyzed, whether by PCM or TEM, due to dust overload.

\section{Discussion}

Limited literature exists on asbestos exposures from working in a research laboratory. However, in a previous exposure assessment, Garcia et al. (2018) [1] evaluated asbestos airborne concentrations associated with standard activities involving wire gauze pads. In conclusion, they found that laboratory technicians and bystanders are exposed to levels of asbestos well below the OSHA PEL during the routine use of new asbestos wire gauze pads. Their exposure assessment also established that well-worn as well as new asbestos-containing wire gauze pads did not produce ambient asbestos fiber concentrations above the 30-minute OSHA regulatory excursion limit. In the current laboratory simulation, various ACM products were evaluated which included gloves, tongs sleeves, and Transite board. The laboratory simulation represented a "worst-case scenario" due to the manner in which the ACM products were manipulated and the chamber environment. All calculated 8-hour TWA concentrations were below the current OSHA PEL of $0.1 \mathrm{f} / \mathrm{cc}$.

Limited literature associated with gloves includes Samimi (1981) [13], who tested gloves in sterilization work (glassware autoclaving) and noted exposures to asbestos were overall higher than the current PEL (ranged from 0.07 to 2.93 f/cc). Similarly, Cherrie et al. (2005) [14] evaluated (new and used) mitts and found airborne concentrations below and above the current PEL (ranged from 0.03 to $0.55 \mathrm{f} / \mathrm{cc}$ ). Neither Samimi's nor Cherrie's articles reported employing TEM in their sample analysis and their results were not characterized beyond total fiber concentration. For this reason, it cannot be determine if the reported exposure by these two researchers was actually from asbestos fibers and what fraction of their samples was actually asbestos. Further, it could not be determined from either of their research if the mitt or glove manipulation was equivalent or similar to the simulation parameters in the current study. Comparison of the findings by Samimi and Cherrie to the current exposure assessment could not be compared because the glove cassettes were overloaded with dust, making quantification of these samples not possible by the prescribed NIOSH methodology. The gloves included in the simulation were old and stressed with the inner liner detached from one of the gloves. The aggressive handling of the gloves ended up generating large amounts of dust, which potentially contributed to the cassettes being overloaded with dust. For future experiments, especially if using the same type of gloves, either a slower pump flow rate or a shorter sampling time should be used to address this issue.

The tong sleeve analyses showed relatively low exposures for two of the PCM samples with the larger concentration of the two being $0.056 \mathrm{f} / \mathrm{cc}$. This concentration, assuming a single episode over 8 hours, yields a TWA of $0.0036 \mathrm{f} / \mathrm{cc}$. If 
we assume four times as much exposure $(4 \times 0.0036 \mathrm{f} / \mathrm{cc})$ in an 8-hour period, the concentration is well below the PEL or $0.014 \mathrm{f} / \mathrm{cc}$. Similarly negligible exposures are reported by TEM for the other tong sleeve samples. However, in one tong sample, the TEM exposure was $0.160 \mathrm{f} / \mathrm{cc}$, approximately 63 percent above the current PEL of $0.1 \mathrm{f} / \mathrm{cc}$. Assuming such exposure in an 8-hour period, the TWA would be $0.01 \mathrm{f} / \mathrm{cc}$, one order of magnitude below the current PEL.

The Transite board sampling yielded 4 unreadable (overloaded) samples ( 3 for PCM and 1 for TEM). Only two of the three TEM samples yielded a quantifiable concentration for these boards. Exposures ranged between 0.210 and $0.320 \mathrm{f} / \mathrm{cc}$, both approximately double and triple the PEL level, respectively. However, if this aggressive board manipulation is performed once in an 8-hour period, the exposure would be well below the PEL in both instances: $0.013 \mathrm{f} / \mathrm{cc}$ and $0.02 \mathrm{f} / \mathrm{cc}$. It is unlikely that one would need to break/shape these boards more than once daily, if at all. More likely than not, the typical lab usage of Transite board would occur sporadically as labs often recycle their customized Transite board for different experiments. The composite sample was also overloaded with dust and was not able to be analyzed by either PCM or TEM.

The conditions simulated during this experiment were intentionally more austere than the expected handling conducted during average laboratory work. While it was determined that in the case of the Transite board and one tong sleeve manipulation that it is possible to generate at least excursion levels of airborne fibers, these levels, are not likely to exceed the 8-hour TWA PEL of 0.1 $\mathrm{f} / \mathrm{cc}$ given intermittent laboratory work activity. However, since asbestos was detected in some of the air samples, it is important to place this exposure in context. The epidemiological data that linked asbestos to asbestosis, lung cancer, and mesothelioma is derived from environments where airborne fibers have been significantly higher than laboratory work (if the findings in these experiments are representative of such exposure). Williams et al. (2009) [3] reported that asbestos exposure during insulation work has been much higher than $1 \mathrm{f} / \mathrm{cc}$. For example, they reported that from insulation work performed in Great Britain, exposure to asbestos has ranged between 68 to $579 \mathrm{f} / \mathrm{cc}$. In the United States, full ship insulation workers had exposures ranging from 3 to $20 \mathrm{f} / \mathrm{cc}(18 \mathrm{f} / \mathrm{cc}$ annually, between 1962-1972 at Puget Sound). These exposures are significantly higher than the ones reported as a result of this simulation.

While none of the air samples were able to be analyzed for the manipulation of gloves in this simulation, past literature has provided results that exposure to asbestos is likely to be relatively low. Cherrie et al. (2005) [14] evaluated asbestos exposure levels associated with the use of unused and artificially aged mitts during glasswork activities. They concluded that workers who wore mitts during glasswork activities were exposed to relatively low levels of airborne chrysotile asbestos fibers. Pierce et al., 2016 [10] published a best estimate for a No Observable Adverse Effect Level (NOAEL) of 89 - $168 \mathrm{f} / \mathrm{cc}$-years for lung cancer and $208-415 \mathrm{f} / \mathrm{cc}$-years for mesothelioma. Based on existing data laboratory use of gloves would not be expected to exceed either of these NOAELs. Considering the 
results of the tests conducted by Cherrie et al. (2005) [14] and the results of the other ACM products evaluated during this research, it is highly likely that asbestos exposure from the use of gloves in a laboratory setting is low and not likely present at levels that would increase the risk of asbestos related diseases.

OSHA's first PEL was $12 \mathrm{f} / \mathrm{cc}$ in 1971; this value was reduced over the years arriving at the current PEL of $0.1 \mathrm{f} / \mathrm{cc}$ (120 times lower than the first PEL; Williams et al. 2007 [3]). In comparison to OSHA's historical occupational exposure limits, the findings of this experiment demonstrate much lower exposures in typical laboratory work. Treating the 30-minute samples as excursion levels, then the OSHA limit is $1 \mathrm{f} / \mathrm{cc}$, which is multiple times higher than the highest reported sample concentration, which was $0.320 \mathrm{f} / \mathrm{cc}$ from Transite board manipulation.

There are asbestos-containing products used in laboratory settings beyond what have been tested in this experiment. However, the findings reported here suggest that laboratory workers are not likely exposed to levels of asbestos that would increase their risk for asbestos-related disease especially taking into account that the bulk of the epidemiological data for asbestosis and cancer comes from very high exposures to asbestos. Further evaluation of ACM products utilized in laboratory settings should be conducted to expand available literature associated with potential asbestos exposure to workers in research laboratories.

\section{Acknowledgements}

This work was funded by the Center for Environmental and Occupational Risk Analysis and Management at the University of South Florida.

\section{Conflicts of Interest}

The authors declare no conflicts of interest regarding the publication of this paper.

\section{References}

[1] Garcia, E., et al. (2018) Evaluation of Airborne Asbestos Exposure from Routine Handling of Asbestos-Containing Wire Gauze Pads in the Research Laboratory. Regulatory Toxicology and Pharmacology, 96, 135-141. https://doi.org/10.1016/j.yrtph.2018.04.020

[2] Virta, R.L. (2006) Worldwide Asbestos Supply and Consumption Trends from 1900 through 2003. US Geological Survey Reston.

[3] Williams, P.R., et al. (2007) A Review of Historical Exposures to Asbestos among Skilled Craftsmen (1940-2006). [Historical Article Research Support, Non-U.S. Gov't Review]. Journal of Toxicology and Environmental Health, Part B: Critical Reviews, 10, 319-377. https://doi.org/10.1080/10937400601034191

[4] Bernstein, D.M., et al. (2005) Comparison of Calidria Chrysotile Asbestos to Pure Tremolite: Final Results of the Inhalation Biopersistence and Histopathology Examination Following Short-Term Exposure. Inhalation Toxicology, 17, 427-449. https://doi.org/10.1080/08958370591002012

[5] Churg, A. (1994) Deposition and Clearance of Chrysotile Asbestos. Annals of Oc- 
cupational Hygiene, 38, 424-425, 625-633.

[6] Blake, C.L., et al. (2006) Assessment of Airborne Asbestos Exposure during the Servicing and Handling of Automobile Asbestos-Containing Gaskets. Regulatory Toxicology and Pharmacology, 45, 214-222. https://doi.org/10.1016/j.yrtph.2006.04.007

[7] Blake, C.L., et al. (2009) Airborne Asbestos Exposure during Light Aircraft Brake Replacement. Regulatory Toxicology and Pharmacology, 54, 242-246. https://doi.org/10.1016/j.yrtph.2009.04.007

[8] Boelter, F.W., et al. (2007) Heavy Equipment Maintenance Exposure Assessment: Using a Time-Activity Model to Estimate Surrogate Values for Replacement of Missing Data. Journal of Occupational and Environmental Hygiene, 4, 525-537. https://doi.org/10.1080/15459620701411109

[9] Goodman, J.E., Peterson, M.K., Bailey, L.A., Kerper, L.E. and Dodge, D.G. (2014) Electricians' Chrysotile Asbestos Exposure from Electrical Products and Risks of Mesothelioma and Lung Cancer. Regulatory Toxicology and Pharmacology, 68, 8-15. https://doi.org/10.1016/j.yrtph.2013.10.008

[10] Pierce, J.S., et al. (2016) An Updated Evaluation of Reported No-Observed Effect Levels for Chrysotile Asbestos for Lung Cancer and Mesothelioma. Critical Reviews in Toxicology, 46, 561-586. https://doi.org/10.3109/10408444.2016.1150960

[11] Garabrant, D.H., et al. (2016) Mesothelioma among Motor Vehicle Mechanics: An Updated Review and Meta-Analysis. Annals of Occupational Hygiene, 60, 8-26. https://doi.org/10.1093/annhyg/mew038

[12] Madl, A.K., et al. (2009) Airborne Asbestos Concentrations Associated with Heavy Equipment Brake Removal. Annals of Occupational Hygiene, 53, 839-857.

[13] Samimi, B.S. and Williams, A.M. (1981) Occupational Exposure to Asbestos Fibers Resulting from Use of Asbestos Gloves. [Research Support, Non-U.S. Gov't]. American Industrial Hygiene Association Journal, 42, 870-875. https://doi.org/10.1080/15298668191420837

[14] Cherrie, J.W., et al. (2005) Exposure and Risks from Wearing Asbestos Mitts. Particle and Fibre Toxicology, 2, 5. https://doi.org/10.1186/1743-8977-2-5 